\title{
Harm, Forgiveness and the Subjectivity of the Victim
}

\author{
Jarosław Horowski ${ }^{1}$
}

Received: 14 September 2021 / Revised: 18 November 2021 / Accepted: 29 November 2021 /

Published online: 7 December 2021

(c) The Author(s) 2021

\begin{abstract}
Forgiveness is one of the most valued decisions in contemporary culture, although it has been emphasised that imprudent forgiveness can cause more harm than good in human relationships. In this article, I focus on the rarely discussed aspect of forgiveness, namely the recovery of subjectivity by the victim in their relationship with the perpetrator. I divide my reflection into three parts. In the first, I deal with the issue of the subjectivity of individuals in social relations. In the second part I present the consequences of the victim's experience of harm, which include, first, the evoking of negative emotions, and subsequently the impact of these emotions on the way the victim functions as a subject in the relationship with the perpetrator. In the third part I show how - thanks to forgiveness - the victim regains subjectivity. Furthermore, I address the moral value of forgiveness. I argue that the regaining of subjectivity by the victim is a premise for recognising forgiveness as a morally good act and illustrate that forgiveness - properly defined - does not pose a threat to the good of people creating a relationship with the perpetrator.
\end{abstract}

Keywords Forgiveness $\cdot$ Subjectivity $\cdot$ Freedom $\cdot$ Emotions caused by harm $\cdot$ The moral value of forgiveness

\section{Introduction}

Although forgiveness in popular culture is assessed positively, its moral value is difficult to define unequivocally. On the one hand, the decision to forgive can lead to the overcoming of crises in interpersonal relationships that result from harm caused by one of the parties, and can restore their relationships (Fiala 2010). It may also be a foundation for overcoming the negative emotions that arise in people who experience harm (Holmgren 1993, 341), and 'free [them] from the inner turmoil that may

Jarosław Horowski

jarohor@umk.pl

1 Nicolaus Copernicus University in Toruń, Faculty of Philosophy and Social Sciences, Toruń, Poland 
come from harbouring grudges' (Murphy 2005, 34). The latter effect of forgiveness is particularly strongly emphasised in the literature relating to various types of counselling (Jaworski 2016). On the other hand, it is impossible to ignore the threats resulting from the decision to forgive, such as indulging bad decisions made by the perpetrators and allowing subsequent ones that might result in further harm to the forgiving persons or others (Kolnai 1974) and the consolidation of bad attitudes in the perpetrators. In this situation, forgiveness may imply a lack of self-respect, violate the moral order (Murphy 2005), and even conflict with concern for the wrongdoers, who are, in a sense, also victims of their actions (Horowski 2020).

The debate surrounding conditions of forgiveness reveals the difficulty in assessing the moral value of forgiveness. Some participants indicate the necessity for perpetrators to change their attitudes as a condition for forgiveness. They hold that the victims may forgive in response to the perpetrators' indicated moral acknowledgment and disavowal of their wrongdoing. Others defend the position of unconditional forgiveness, according to which moral acknowledgment indicated by the perpetrator is not a condition of the victim's shift in attitude (Zaibert 2009). The first position - referred to as the conditional approach and combining forgiveness with repentance - is occupied, for example, by Aurel Kolnai (1974), Jeffrie Murphy (2003) and Charles Griswold (2014). In turn, unconditional forgiveness is allowed and appreciated, for example, by Margaret R. Holmgren (1993), Pamela Hieronymi (2001) and Jacques Derrida (2002).

In this article, I pay attention to a specific aspect of forgiveness that is rarely taken into account when analysing the act of forgiveness, and which, in my opinion, is important in determining the moral value of forgiveness. My thesis contends that forgiveness is an act by which the victims regain subjectivity in their relationships with the perpetrators, as well as in the broader context of social relationships in which the victims and the perpetrators participate. This thesis implies another thesis concerning harm. I hold that the experience of harm poses a threat to the subjectivity of the victims and often causes them to lose their subjectivity (also due to the ritual of repentance, treated in the dominant culture as a precondition for the perpetrators to receive forgiveness). I am aware that taking up the issue of relationship between forgiveness and subjectivity how subjectivity is understood needs to be explained, due to the ambiguity of this category, and so the first part of the present work will be devoted to this issue. Moreover, consequently, I argue that the indication of this specific aspect of forgiveness, which is the regaining of subjectivity by the victims, becomes an argument in favour of recognising forgiveness as a morally good act, regardless of whether it is a consequence of a change in the perpetrators' attitude, or, on the contrary, an unconditional act.

For the clarity of reflection, I assume that the analysis refers to a situation of actual harm and I limit the analysed problem to the case in which forgiveness is a decision made by the victim in relation to the perpetrator. Therefore, I omit a few problems raised in discussions about forgiveness, such as, for example, the problem of who has the right to forgive (victim, third party, or even the perpetrator - forgiving him/herself) and what the target of forgiveness is - the perpetrator or his/her deed. These issues are widely discussed in the literature (Russell 2020). I therefore consciously simplify the situation, focusing attention on the essence of the problem. 
The analysis is divided into three parts. In the first part, I explain how the subjectivity of individuals in social relationships is understood in this analysis. In the second part I show how the experience of harm can lead to the loss of subjectivity by the victims in the relationships with the perpetrators. In the third part I present forgiveness as a means through which the victims regain subjectivity in these relationships, thanks to which forgiveness can be considered morally good. To prove this, I must refer to several difficulties in understanding the act of forgiveness, such as changing the emotional relationship of the victims to the perpetrators or the moral problem of linking forgiveness with refraining from punishing the perpetrators.

\section{Subjectivity of Individuals in Social Relations}

The term 'subjectivity' derives from the term 'subject'. This term indicates a being to which can be assigned features such as self-awareness, self-knowledge, independence, self-determination, identity, autonomy, agency and related responsibility, effectiveness, intentionality and freedom understood as the possibility of creating oneself (Salamucha 2021). Subjectivity, as such, can be understood either as a property of a given being (subject) - static understanding - or as a property of the action taken by it - dynamic understanding.

Subjectivity is close to freedom and is defined by freedom. One could say that subjectivity is a feature of free people - people whose action depends on their free decisions. If individuals do not make free decisions in the social groups to which they belong, they are not subjects. Such people undertake actions, the goal and course of which are determined by other people. They are driven by others.

Despite the fact that subjectivity is close to freedom, one needs to distinguish between subjectivity and freedom. I understand the first phenomenon - subjectivity - as being related to functioning in interpersonal relations. In turn, the term 'freedom' refers to the very process of making decisions. In order to distinguish between these two realities, they should be briefly characterised.

In this analysis, the neo-Thomistic theory of human action determines the way I understand human freedom. This theory - referring to the thoughts of Thomas Aquinas - was developed in the twentieth century by, for example, Étienne Gilson (2002), Jacques Maritain (1990), Robert Spaemann (2006), Karol Wojtyła (1979) and Mieczysław Krąiec (2004). In this theory, two levels of human functioning are distinguished - sensual (manifesting itself in emotions) and mental (related to rational decisions). These two spheres of human nature should be integrated when making decisions. However, a decision can be considered free when sensuality is subordinated to rationality, that is, the person undertakes actions whose goal is set by reason. Otherwise, if the goal of the action is indicated by the senses, and the reason is used instrumentally to find a way to achieve the goal set by those senses, the action cannot be considered free (Crosby 1996; Maryniarczyk 1999; Krapiec 2004). Freedom is difficult, because sensuality has its own dynamics. Everything that happens in social relationships in which given individuals participate evokes emotions that are important when making decisions about their own actions. These emotions may make it difficult 
or impossible to decide on an action deemed appropriate by reason in a given situation for the good of different people experiencing the effects of said action. In this way, decisions made by one person and eliciting emotions in the second person can limit the freedom of the second person. In a sense, the second person becomes a 'prisoner' of the emotions that are aroused in them.

I distinguish subjectivity from freedom, linking the former with social relations. First of all, it is social relations that constitute the context for subjective activities. The determinant of subjectivity is therefore the agency of the individual in social relations (Archer 2000). Referring to subjectivity, it should be noticed that subjectivity develops because independence, self-determination and agency do not characterise people at the moment of their birth, but can emerge only with the development of rationality and freedom. Moreover, subjectivity can reach different levels of development. The high level of development of the above-mentioned features, such as freedom, independence, autonomy and selfdetermination, prevents such people from being pressured by the social group to which they belong, and in consequence they are able to make decisions influencing social relations (their activity can be defined as subjective). At the same time, a high level of development of these features may not be achieved, and then the individual submits her- or himself to the group, functioning in accordance with the patterns imposed by others. In other words, subjectivity can be assigned to those members of social groups who participate in making decisions and who, with their decisions, influence the functioning of these social groups. Individuals can be characterised as subjects if they adopt an attitude of solidarity or opposition to the actions of other members of the group. However, it is difficult to consider, in particular, the attitude of conformism as a subjective attitude (Wojtyła 1979). Conformists are people who are influenced by others; they do not make independent decisions and are people who, instead of influencing reality, submit to the circumstances of the moment. It is easy to direct the actions of such people, not so much by orders as by triggering certain emotions in them that will result in particular behaviours.

When analysing subjectivity, one should always take into account the context that is the point of reference for recognising a given activity as subjective or characterised by the lack of subjectivity. For example, in many situations - even in road traffic - people obey the rules established in a given society, regardless of the level of development of such features as independence, freedom or autonomy. However, the same people may have different levels of subjectivity in social relationships if moral dilemmas are the reference point for action. In reflection on forgiveness, it is the moral context of social relations that is taken into account when analysing the subjectivity of individuals in these relations.

In this analysis, the title category is subjectivity, because the ability of victims to create relationships in which both sides of the harm participate is the basic point of reference. At the same time, the analysis mainly refers to the understanding of subjectivity as internal freedom, that is, the ability to direct actions as indicated by reason and will. 


\section{Harm as a Source of Loss of Subjectivity by the Victim in the Relationship with the Perpetrator}

Reflection on the harm caused in the life of a given person by the conscious action of another usually touches one of the dimensions of it - first, it is reduced to the loss of a specific good by the aggrieved person, and in a more in-depth analysis it is indicated that the harm is an attack on the dignity and value of the victim, because they are demeaned or even undermined by this act (Murphy \& Hampton 2002, 25). It is less commonly recognised that other very serious and negative consequences are triggered in victims by the actions of the perpetrators - these include, firstly, arousing in victims a range of hostile, negative emotions such as hate, anger, resentment, indignation, disgust, contempt and scorn towards the perpetrator - and consequently the victims are in danger of transforming these negative emotions into a conscious or unconscious desire for revenge. In this process, initiated by the experience of harm, it is worth paying attention to another hardly discernible aspect, namely the victims' loss of subjectivity. In a sense, perpetrators evoke specific emotions in victims and influence their subsequent decisions, that is, they begin to direct the actions of victims. In order to recognise this problem, it is necessary to look at the effects of the harm on the victims.

Although the list of negative emotions caused by the experience of hurt is long, it is worth noting that they can be divided into two groups. The first group includes emotions directed towards the moral act. These perform appraising, communicating and sanctioning functions. They appraise the action as morally wrong, they convey to the wrongdoers that appraisal and they sanction the wrongdoers for what they did (Aumann \& Cogley 2019). It can be said that they play a positive and valuable role in the functioning of individuals in interpersonal relationships, especially from the perspective of the possibility of experiencing another harm (Hieronymi 2001, 546; Murphy \& Hampton 2002, 16-17). Emotions directed at the perpetrators belong to the second group. For example, anger and indignation are directed at the moral acts, but moral hatred is directed at persons. Assigning individual emotions to any of the groups is simple on the theoretical level. In practice, morally bad acts are related to the perpetrators, so the emotional reaction to the act becomes at the same time the arousal of specific emotions directed at the acting persons (Kolnai 1974, 97; Murphy \& Hampton 2002, 55; MacLachlan 2010). These emotions can in turn become reactive passions and can very easily lead to retributive actions (Griswold 2014). Consequently, the experience of harm can lead to the emergence and perpetuation of negative attitudes such as hate, malice or vindictiveness in the victims. Thus, experiencing harm can make victims what they do not want to be, and this can cause actions that are negatively perceived and unwanted by the victims.

In a way, these consequences of harm are the primary point of reference for the analysis by Joseph Butler (1827). When interpreting his sermons on resentment and forgiveness, it should be noted that Bishop Butler, as theologian and pastor, addresses the spirituality of his audience. The key dimension of spirituality is morality. Butler tries to answer the question of what consequences for the 
spirituality of an individual will arise from the emergence of such vices as hatred, malice and revenge, which may develop when emotions arising from the harm are not overcome, that is, hasty and sudden resentment become settled and deliberate (Butler 1827). Thus, Butler recognises forgiveness as a way to overcome the emotions triggered by the experience of harm. His words are an expression of concern for the spiritual development of the audience, which is manifested through moral development.

Emotions arising from the experience of harm and the dynamics of their development in victims are the subject of numerous analyses in psychological and philosophical literature, in which affects, passions and actions are distinguished and the subject of given emotions is identified (Brudholm 2010; Aumann \& Cogley 2019). Moreover, emotions are also the subject of reflection in the philosophy of law, where answers not only to the question of how negative emotions shape legal systems, but also to how legal systems are used to express negative emotions aroused in victims after experiencing harm, are sought (Murphy 2005; Nussbaum 2016). These issues are therefore widely discussed.

Negative emotions and attitudes for which particular emotions may become the foundation are not the subject of this reflection. The subject is, rather, the issue of the loss of subjectivity by the victims in their relationships with the wrongdoers. However, the consideration of the topic of emotions is deliberate. The issues of emotions and attitudes evoked by them and the subjectivity are closely related. In order to understand this, one must first refer to the understanding of subjectivity as acting in accordance with the suggestions of reason, even in the context of aroused emotions that lead to contrary decisions. If the subjectivity of an individual consists in obedience to the reason that indicates the best solution in a given situation, then one can speak of a lack of subjectivity when this person is provoked by the actions of another person to actions not indicated by reason. In other words, it is difficult to argue that an individual is the subject of an action if he or she - led by hatred, malice or revenge - takes actions which, from the perspective of reason, are irrational. Of course, the victim under the influence of these emotions does not stop using his or her mind and does not stop thinking, but in this situation the mind becomes a tool for finding the best way to express negative emotions. On the other hand, subjectivity is preserved if the individual follows the dictates of reason, even if such action requires the control of intense and opposing emotions.

The above statement is based on the controversial assumption that actions originating in negative emotions arising from the experience of harm are irrational. This is expressed, inter alia, by Butler: 'hatred, malice, and revenge, are directly contrary [...] to the nature and reason of the thing itself' (Butler 1827). One could challenge the above statement, arguing that victims have the right to make decisions about actions that are a kind of 'getting even' or revenge. However, this thesis can be questioned by referring to specific situations. Since harm occurs often in relationships with close relatives, let us refer to an example of this type, namely the breakdown of a marriage due to abandonment, betrayal by one of the spouses, and the victim's attitude towards the offending spouse. In this situation, there are two main people involved - the betraying and abandoning perpetrator, and the victim, the betrayed and abandoned person who has to decide how the perpetrator will be treated. There 
are also other people involved in the situation - these include, for example, the children of the spouses. If the harming decision had not been taken by one of the spouses, the other person would pursue the good of the husband/wife for several reasons: firstly, because of concern for this person, because he or she took responsibility for him or her on the day of their wedding; secondly, because of the common good that their marriage is; thirdly, for the sake of their children, whose development and happiness are conditioned by good relationships with their parents, and the better each parent functions, the better these relationships will be. The breakdown of a marriage due to the abandonment or betrayal of one of the spouses does not change the last determinant of the decisions made by the victim. While it is difficult to care for the spouses' broken relationship, caring for the children - for their well-being and development - implies caring for the spouse who is the children's only mother or father. Striving to break the relationship with the ex-spouse, turning away from that person, trying to get even (for example, by undermining the value of the offender), and even indifference to the offender's good, or demanding repentance or apology, which in a given context are forms of hidden revenge (Nussbaum 2016), are actions whose consequences will be experienced not only by the unfaithful spouse, but also by the children. Paradoxically, in order to seek the welfare of children, one should look after the welfare of an unfaithful spouse. In this situation, acting in accordance with reason is acting for the good of the harming person.

To sum up the above analysis, if the experience of harm evokes emotions in the victims, directed not only at the wrong deeds, but also at the perpetrators, and then these emotions find expression in action, the victims of which are not only the perpetrators, but also other people, it can be said that the wrongdoers - by evoking negative emotions - provoked the victims to act contrary to reason, doing something unwanted under normal circumstances, and therefore that the wrongdoers directed the actions of their victims. It is the perpetrators who are the ultimate source of certain decisions, even if at first glance these decisions are made by the victims. The perpetrators' actions first determine the way the victims experience the situation, and, consequently, the behaviour of the victims. Referring to the issue of subjectivity, it can be said that the source of the victims' activity is not in themselves, but in the perpetrators, who also direct the victims' decisions. This is the first argument in favour of the claim that harm tends to deprive victims of subjectivity.

The second argument is related to persuading victims to act in a way that is morally evil, and this is the argumentation presented in the above analysis, deepened by the moral aspect. When analysing the subjectivity of the victims, it is worth paying attention to the moral value of paying back of harm suffered. When taking up this topic, it should be assumed that a person strives in his or her actions not only for his or her own good, but also for the good of those with whom he or she maintains relationships. As Butler writes in his sermons: 'general benevolence is the great law of the whole moral creation' (Butler 1827). Butler's reflection is based on the assumption that people want to support rather than hurt those with whom they have relationships. If individuals experience pain or suffering due to a specific action of others, they evaluate these acts as morally wrong. Thus, striving to get even is the undertaking by the victims of actions they previously judged to be morally negative, and is a rejection of the principle of caring for another human being. Therefore, it should be assumed that the action 
resulting from anger and the seeking of compensation for the harm would never have been taken by the victims had it not been for the prior action of the perpetrators. It is worth referring to Butler's words again: 'For every man naturally feels an indignation upon seeing instances of villainy and baseness, and therefore cannot commit the same, without being self-condemned' (Butler 1827). In this context, it can therefore be concluded that specific actions of the victims do not find their source in the victims themselves and their efforts to create a better reality, but that the source of these actions lies in the perpetrators, whose decisions provoke specific, initially unwanted behaviours of the victims.

The last two arguments for depriving victims of subjectivity are related to the ritual of repentance, seen as a condition of forgiveness. This ritual is discussed in detail in the literature. For victims to forgive, the wrongdoers must understand the suffering they have caused, they must feel regret for the injuries they caused, they must disavow this kind of wrong again and they must credibly commit to changing their behaviours (Griswold 2014, 51). The decision to forgive people who are not mature enough to change their behaviour is even seen as imprudent (Horowski 2019). The third argument for depriving victims of subjectivity is related to the fact that the above-mentioned conditions of forgiveness - established in culture - influence the behaviour of victims in relationships with the perpetrators. Therefore, they do not allow for a decision to forgive when the perpetrators do not express repentance, that is, they create a specific scheme of action that should be applied in a situation of harm. Fourth, the above-mentioned scheme makes the actions of the victims dependent on the actions of the perpetrators. It is the wrongdoers who have the initiative all the time. They may be seeking forgiveness, or they may not care about forgiveness. Failure by the perpetrators to meet the conditions justifying forgiveness prevents victims from choosing to forgive. Victims become 'prisoners' of a specific situation, and the key to that prison cell is in the hands of those who previously hurt them. Lack of any manifestations of repentance on the part of the perpetrators or lack of desire to express regret may result in the victims being doomed to unforgiveness until the end of their lives. This is pointed out by Jessica Wolfendale, who draws the conclusion that conditional accounts are pointless (Wolfendale 2005, 352-353).

Summing up, it can be said that the perpetrators, when committing an harming act, not only hurt other people, but also first influence the emotions of their victims, and thus provoke these victims to act contrary to reason and in a way perceived by the victims as morally negative. Moreover, recognising the change of attitude of the perpetrators as a condition for prudent forgiveness becomes a factor that prevents victims from forgiving and limits the subjectivity of victims in relationships with perpetrators and in the wider context of social relationships in which victims and perpetrators participate.

\section{Forgiveness and the Subjectivity of the Victim in Relationship with the Perpetrator}

The analysis carried out in the first part of the article leads to the conclusion that forgiveness can be considered a decision that enables the victims to retain or regain subjectivity in their relationships with the perpetrators, and, consequently, that 
forgiveness is a good decision. However, in order to formulate such a thesis, one must first try to define forgiveness. Jeffrie Murphy, starting his reflection on forgiveness, states that this term covers 'amalgamation of definition and justification' (Murphy 2003). Depending on how forgiveness is defined, the thesis that forgiveness contributes to the recovery of subjectivity, and that it is morally right, turns out to be either true or untrue.

Forgiveness is closely related to emotions (Warmke 2015) and is even considered an emotion itself (Szigeti 2014). Murphy, referring to the understanding of forgiveness expressed by Butler, states that the forgiving person is the 'one who has, on moral or religious grounds, forsworn resentment - forsworn the very personal response of anger or sometimes even hatred that one naturally (and perhaps properly) initially feels when one believes that one has been wronged by another' (Murphy 1982). Similarly, Holmgren holds that to forgive means 'to overcome any negative feelings the victim harbours towards the offender - resentment, contempt, hatred, indignation' (Holmgren 1993, 341). It is worth noting that in these definitions 'to forgive' means 'to forswear' or 'to overcome', and that the emotions mentioned by the authors are directed both at deeds (anger) and at perpetrators (hate). Is overcoming negative emotions a process on the level of emotions, or do the mental powers - reason and will - play an important role in it? (Warmke 2015) Moreover, does forgiveness imply a change of attitude towards painful experiences, or is it just a change of attitude towards perpetrators? And consequently, is it possible and necessary (and good) to change one's attitude towards the harm one has experienced?

The key to solving these problems is to answer the first question. If forgiveness were an emotional process, the discussion of its moral value would be meaningless, because individuals experiencing harm could not influence their emotions with their mental faculties - reason and will. They could neither change the attitude towards the perpetrators nor the negative decisions the perpetrators made. Then the process of forgiveness would be spontaneous, beyond the control of the victims (Warmke 2015). I therefore argue that forgiveness is a change of attitude towards perpetrators - a change made by will, guided by reason - justifying the change. I argue that forgiveness is striving for the good of the perpetrators, caring for them even though their actions previously led to the suffering of the victims. One of the dimensions of this process is the sublimation of emotions, consisting of 'convincing' them (reason) and 'drawing' them to actions (will) aimed at the good of the perpetrators. By defining forgiveness in this way, it is possible to conclude that forgiveness also occurs when the victims continue to have negative emotions, especially towards the acts that cause suffering. However, when the decision to forgive is made, these emotions are controlled by reason and will. Brandon Warmke - pointing to the link between forgiveness and the change of norms governing action towards the perpetrator - recalled three descriptions of forgiveness that fit my position. Glen Pettigrove is the author of the first two. According to him, 'to forgive' means 'to forswear hostile reactive attitudes and retaliation toward the wrongdoer' and 'to treat the wrongdoer with an appropriate level of benevolence' (Pettigrove 2004, 385). The author of the third one is Warmke himself, who claims that 'to forgive' means 'not to treat the wrongdoer in ways that would typically be characterized as blaming behaviours' (Warmke 2016, 693). Butler also seems to take a position that 
forgiveness is an attitude, conditioned by a decision of reason and will, because he claims that forgiveness results in 'real goodwill towards the offender' (Butler 1827). This is confirmed by Murphy, who argues: 'In the second of these sermons, Butler [...] - rightly, in my judgment - characterizes forgiveness as primarily an internal matter, a change of heart. It often does, of course, have external behavioral consequences, but its essence is internal [...] It is not itself an emotion or passion but is rather, according to Butler, the overcoming or limiting of certain passions, namely, the vindictive passions that are naturally aroused when we are wronged by others' (Murphy 2005, 34).

Referring to this definition of forgiveness, four arguments can be invoked in favour of the thesis that forgiveness is the recovery of subjectivity by victims in their relationships with perpetrators. First, forgiveness is a decision that requires taking control of negative emotions. It is not an action taken under the influence of those emotions, but an action guided by reason. Forgiveness implies refraining from the settling of accounts (which is induced by emotions) in order to take actions through which good will be achieved by all persons involved in a given situation. This can be seen in the example of betrayal. Forgiveness consists in dealing with negative emotions in such a way that the action taken by the betrayed spouse leads to the good of the children of the couple, even if the means to achieve this goal is to refrain from settling accounts with the unfaithful spouse, maintaining contact with him or her, and supporting him or her so that parental functions can be fulfilled in the best possible way. Forgiveness, therefore, is making decisions that seem best to the victim in a given situation, ignoring the negative emotions aroused by marital infidelity, and therefore also treating the spouse in such a way that he or she does not deserve because of the harm caused by him or her. It should be emphasised that it is important, above all, to subordinate the action to reason, which indicates the best solution in the given circumstances and to ignore the emotions that have been caused by the perpetrator's actions that can lead to making decisions different from those suggested by reason. ${ }^{1}$

Second, forgiveness finds expression in actions that are morally good, that is, those chosen by the individual not suffering the harm. This argument is based on several assumptions. First, there are actions that certain people consider good and desirable, and actions that the same people consider bad and undesirable. Actions such as ignoring people, displeasing them, or treating them unkindly are actions belonging to the latter group - actions perceived as wrong and necessary to avoid. Finally, the experience of harm prompts the victims to take actions belonging to the second group. This means that these actions have, in a sense, a cause external to the acting persons. Thus, if the victims avoid actions that they perceive as wrong and undesirable, refer in their own actions to their own original assessment of the

\footnotetext{
${ }^{1}$ The subjectivity of the victims, consisting in taking control over their emotions by reason and will, is particularly noticeable in the situation of invitational forgiveness, when the victims, through their forgiveness, 'inspire moral acknowledgment and moral regret - and even moral transformation' of the offenders (Govier \& Hirano 2008, 434). However, this is a special case of forgiveness that requires separate analysis.
} 
moral value of a given action, and are not provoked to act differently, they retain subjectivity.

The last two arguments relate to the ritual of repentance. According to the third, forgiveness - especially if it is an unconditional action - is a decision independent of the culturally established patterns according to which the condition of forgiveness is the repentance expressed by the wrongdoers. Fourth, unconditional forgiveness is not conditioned upon the wrongdoers' prior actions, that is, their expressions of repentance and willingness to accept forgiveness or a lack of interest in the forgiveness given by the victims, which is expressed through unrepentant behaviour.

Even though it seems easy to link forgiveness with regaining subjectivity in a relationship, the aim of these analyses goes much deeper and touches upon the moral dimension of forgiveness. While regaining subjectivity in relationships can be judged as good, the means to achieve this goal - forgiveness - can still raise moral doubts, as I mentioned in the introduction. If the means to an end is wrong, the action in question cannot be judged as good. Forgiveness seems to be a case in point. Forgiveness may seem unfair because, in a sense, it is acceptance of the wrong done by the perpetrators, especially when it is not combined with repentance expressed by the perpetrator. In the context of harm done by someone, punishment seems more justified. Moreover, forgiveness may appear imprudent, as it may be dangerous for the victims and for others who may experience harm. As a result, punishment seems more prudent. Should decisions therefore be made in order to maintain subjectivity that may lead to the negative effects mentioned above? In order to consider forgiveness as a morally good act, these doubts must be dispelled.

The problem highlighted here arises from a specific understanding of forgiveness and a specific understanding of punishment. According to this (stereotypical) understanding, forgiveness is related to the cessation of punishment. Conversely, the imposition of punishment is viewed as an expression of unforgiveness (Zaibert 2009; Fiala 2010). However, if punishment has a preventive and educational significance, then punishment may be considered as an expression of concern for the good of perpetrators who, through their actions, harm not only other people, but also themselves. Thus, the purpose of punishment is to change the attitude of the perpetrators and to enable them to achieve a certain good. Such punishment cannot be understood as revenge (or vengeance), because it is not 'the infliction of suffering on a person in order to satisfy vindictive emotions or passions' (Murphy 2003, 17). On the contrary, resignation from punishment may be an expression of indifference to the good of the perpetrators, that is, an expression of a lack of forgiveness. Letting the perpetrators experience the consequences of the behaviour they have committed may even be a sign of revenge. If the stereotypical understanding of the relationship between punishment and forgiveness is rejected, then it can be assumed that one of the dimensions of forgiveness, that is, adopting a positive attitude towards perpetrators, is striving to impose a punishment that leads to a positive transformation of the wrongdoers (Warmke 2013; cf. Zaibert 2010). This means it is possible 'to punish with forgiveness as opposed to punishing with blame' (Lacey \& Pickard 2015, 669). Concern for the good of wrongdoers does not have to be the same as taking actions that will please them. In many situations, in order to care for the good of specific people, one must take actions that are unpleasant for them. Moreover, they may not 
know that the victims have forgiven them. The position matching this analysis is that of Leo Zaibert (2009), who recommends distinguishing between forgiveness understood as a mental phenomenon and a communicative act.

In light of the above analysis, moral doubts associated with forgiveness are dispelled. Although the attitude of victims to perpetrators in the decision to forgive changes, this change cannot be understood as accepting the wrong or allowing another harm. Forgiveness is a change of attitude towards perpetrators and adopting an attitude of concern for their good - an attitude which, depending on the circumstances and the level of understanding by the perpetrators of the harm done by them, can be expressed both in resignation from punishment and in seeking punishment for the perpetrators. Thus, forgiveness understood in this way is not contrary to the victims' respect for themselves, with concern for their dignity, or with respect for the moral order Holmgren (1993). These doubts related to the decision to forgive, and expressed by, for example, Murphy (2003 7-8) can be dispelled.

\section{Conclusions}

The purpose of this analysis was to show that forgiveness is the means for victims to regain subjectivity in their relationship with perpetrators, and consequently to indicate that forgiveness is a morally good act. It was shown in the analysis that forgiveness is a transformation of the inner attitude towards perpetrators, but that this does not mean that victims cannot seek to punish the perpetrators if it is required for the good of the perpetrators and other persons involved in the relationship.

The analysis concerned only the philosophical aspects of forgiveness. It did not include the psychological aspects, such as the stages of the spiritual journey towards forgiveness experienced by the aggrieved. This means that, for example, the analysis did not address the issue of pressure on the victims to forgive the perpetrators. Such pressure may be exerted by culture or by people close to the victims and perpetrators. Moreover, in many cases, the decision to forgive can be made hastily and because of fear of working through the harm experienced or fear of losing relationships with wrongdoers. Consequently, the conclusion that every act of forgiveness is an expression of subjectivity and is good cannot be drawn.

On the other hand, recognising the aspect of forgiveness discussed in this article may prove important to many people who experience harm. Losing subjectivity and 'imprisonment' in the experience of harm can be the imperceptible result of painful events. This manifests itself in the inability to positively shape relationships in which both victims and perpetrators participate. The situation of a specific 'imprisonment' may last for years and be perceived as a situation with no exit. It is therefore worth noting that forgiveness is a way to break free from this prison and regain control of relationships whose history also includes the experience of harm.

It is also worth noting that the analysis leads to the conclusion that forgiveness does not have to be conditioned by repentance. Combining these two phenomena - positively perceived and desired in themselves - may be a source of limitations for victims regaining subjectivity in their relationships with perpetrators. 
Availability of Data and Material Not applicable.

Code Availability Not applicable.

Authors' Contributions Not applicable.

\section{Declarations}

Conflicts of Interest/Competing Interests The author declares that he has no conflict of interest.

Ethics Approval The article complies with current ethical standards.

Consent to Participate Not applicable.

Consent for Publication Not applicable.

Open Access This article is licensed under a Creative Commons Attribution 4.0 International License, which permits use, sharing, adaptation, distribution and reproduction in any medium or format, as long as you give appropriate credit to the original author(s) and the source, provide a link to the Creative Commons licence, and indicate if changes were made. The images or other third party material in this article are included in the article's Creative Commons licence, unless indicated otherwise in a credit line to the material. If material is not included in the article's Creative Commons licence and your intended use is not permitted by statutory regulation or exceeds the permitted use, you will need to obtain permission directly from the copyright holder. To view a copy of this licence, visit http://creativecommons.org/ licenses/by/4.0/.

\section{References}

Archer, M. S. (2000). Being human, the problem of agency. Cambridge University Press.

Aumann, A. G., \& Cogley, Z. (2019). Forgiveness and the multiple functions of anger. Journal of philosophy of. Emotion, 1(1), 44-71. https://doi.org/10.33497/jpe.v1i1.7

Brudholm, T. (2010). Hatred as an attitude. Philosophical Papers, 39(3), 289-313. https://doi.org/10. $1080 / 05568641.2010 .538912$

Butler, J. (1827). Fifteen sermons preached at the rolls chapel. Cambridge: Hilliard and Brown. Available at: http://anglicanhistory.org/butler/rolls/index.html. Accessed 25 Apr 2021.

Crosby, J. F. (1996). The selfhood of the human person. The Catholic University of America Press.

Derrida, J. (2002). On cosmopolitanism and forgiveness. Routledge.

Govier, T., \& Hirano, C. (2008). A conception of invitational forgiveness. Journal of Social Philosophy, 39(3), 429-444.

Fiala, A. (2010). Justice, forgiveness, and care: A pragmatic balance. Ethical Perspectives, 17(4), 580602. https://doi.org/10.2143/EP.17.4.2059847

Gilson, Étienne. 2002. Thomism. The philosophy of Thomas Aquinas, trans. L. K. Shookand, A. Maurer. Toronto: Pontifical institute of mediaeval studies.

Griswold, C. L. (2014). Forgiveness. A philosophical exploration. Cambridge University Press.

Hieronymi, P. (2001). Articulating an uncompromising forgiveness. Philosophy and Phenomenological Research, 62(3), 529-555. https://doi.org/10.2307/2653535

Holmgren, M. R. (1993). Forgiveness and the intrinsic value of persons. American Philosophical Quarterly, 30(4), 341-352.

Horowski, J. (2019). Education for forgiveness in the context of developing prudence. Ethics and Education, 14(3), 316-332. https://doi.org/10.1080/17449642.2019.1624483

Horowski, Jarosław. 2020. Education for self-forgiveness as a part of education for forgiveness. Journal of Philosophy of Education: 1-17. https://doi.org/10.1111/1467-9752.12500. 
Jaworski, Romuald. 2016. Przebaczenie w psychoterapii [forgiveness in psychotherapy]. Paedagogia Christiana 37: 141-159. https://doi.org/10.12775/PCh.2016.027.

Kolnai, A. (1974). Forgiveness. Proceedings of the Aristotelian Society, 74(1), 91-106. https://doi.org/10. 1093/aristotelian/74.1.91

Krąpiec, M. A. (2004). Ludzka wolność i jej granice. Polskie Towarzystwo Tomasza z Akwinu.

Lacey, N., \& Pickard, H. (2015). To blame or to forgive? Reconciling punishment and forgiveness in criminal justice. Oxford Journal of Legal Studies, 35(4), 665-696. https://doi.org/10.1093/ojls/ gqv012

Maritain, J. (1990). An introduction to the basic problems of moral philosophy. Magi.

Maryniarczyk, A. (1999). Czym jest ludzka wolność? Paedagogia Christiana, 3, 5-18.

Murphy, J. G. (1982). Forgiveness and resentment. Midwest Studies in Philosophy, 7, 503-516. https:// doi.org/10.1111/j.1475-4975.1982.tb00106.x

Murphy, J. G. (2003). Getting even, forgiveness and its limits. Oxford University Press.

Murphy, Jeffrie G. 2005. Forgiveness, self-respect, and the value of resentment. In Handbook of forgiveness, edited by Everett L. Worthington, Jr., 33-40. : Routledge.

Murphy, J. G., \& Hamptom, J. (2002). Forgiveness and mercy. Cambridge University Press.

Nussbaum, M. (2016). Anger and forgiveness, resentment, generosity, and justice. Oxford University Press.

Pettigrove, G. (2004). The forgiveness we speak: The illocutionary force of forgiving. The Southern Journal of Philosophy, 42(3), 371-392.

Russell, L. (2020). The who, the what, and the how of forgiveness. Philosophy Compass, 15(3), e12656. https://doi.org/10.1111/phc3.12656

Spaemann, Robert. 2006. Persons: The difference between "someone” and "something”. Trans. O. O’Donovan. Oxford: Oxford University Press.

Szigeti, A. (2014). Focusing forgiveness. The Journal of Value Inquiry, 48(2), 217-234.

Warmke, B. (2013). Two arguments against the punishment-forbearance account of forgiveness. Philosophical Studies, 165, 915-920. https://doi.org/10.1007/s11098-012-9996-2

Warmke, B. (2015). Articulate forgiveness and normative constraints. Canadian Journal of Philosophy, 45(4), 490-514. https://doi.org/10.1080/00455091.2015.1101305

Warmke, B. (2016). The normative significance of forgiveness. Australasian Journal of Philosophy, 94(4), 687-703. https://doi.org/10.1080/00048402.2015.1126850

Wojtyła, K. (1979). The acting person: A contribution to phenomenological anthropology. Springer.

Wolfendale, J. (2005). The hardened heart: The moral dangers of not forgiving. Journal of Social Philosophy, 36(3), 344-363.

Zaibert, L. (2009). The paradox of forgiveness. Journal of Moral Philosophy, 6(3), 365-393. https://doi. org/10.1163/174552409X433436

Zaibert, Leo. 2010. Punishment and forgiveness. In punishment and ethics, edited by Jesper Ryberg, and J. Angelo Corlett, 92-110. London: Palgrave Macmillan. https://doi.org/10.1057/9780230290624_6.

Publisher's Note Springer Nature remains neutral with regard to jurisdictional claims in published maps and institutional affiliations. 